Article

\title{
Does Social Media Use Influence Entrepreneurial Opportunity? A Review of its Moderating Role
}

\author{
Joo Y. Park ${ }^{1}$ (D), Chang Soo Sung ${ }^{2, *}$ and Il Im ${ }^{1}$ \\ 1 School of Business, Yonsei University, Seoul 120-749, Korea; park3500@naver.com (J.Y.P.); \\ il.im@yonsei.ac.kr (I.I.) \\ 2 Department of Technology Entrepreneurship (graduate), Dongguk University, Seoul 100-272, Korea \\ * Correspondence: redsun44@dongguk.edu; Tel.: +82-2-2088-3737 (ext. 1110)
}

Received: 20 July 2017; Accepted: 1 September 2017; Published: 8 September 2017

\begin{abstract}
Social media platforms are an indispensable part of entrepreneurship practices. They offer entrepreneurs a platform for business growth and brand development. However, little is known about the effect of social media use on identifying entrepreneurial opportunities. Utilizing social cognition theory, this research focuses on how certain factors-prior knowledge, alertness, and social media-may impact two aspects of opportunity: the discovery and the creation of entrepreneurial opportunity. This study focuses on the investigation of the moderating role of social media use on entrepreneurial opportunities. The findings have important practical and academic implications for how social media impacts entrepreneurship and can be used to increase the ability of entrepreneurs to find new opportunities.
\end{abstract}

Keywords: social cognitive theory; alertness; prior knowledge; social media; entrepreneurial opportunity

\section{Introduction}

Entrepreneurial opportunities are important for entrepreneurs looking to start a business because business creation is a process of identifying and exploiting potential opportunities [1]. Thus, identifying and capturing opportunities is fundamental to the entrepreneurship process. However, this process is often challenging for entrepreneurs as they try to create their own businesses and increase financial performance. Many researchers have explored when and how entrepreneurs recognize and exploit opportunity using available resources [2-6]. The ability to succeed has been explained in various different ways, ranging from individual differences [7,8] to sustainable entrepreneurship [9].

In recent studies on entrepreneurial opportunities, social activities and social networks have attracted the attention of researchers seeking to identify ways entrepreneurs obtain entrepreneurial opportunities $[10,11]$. Strong social capital and networks facilitate finding business opportunities and encourage individuals to become entrepreneurs [10]. Social media platforms and applications are often considered as useful tools for entrepreneurship. They enable entrepreneurs to easily identify changes and opportunities in business creation through interactions and communications with peers on the networks. Social media offers opportunities to reach target customers and generate new ideas for starting a business. Similarly, small-scale entrepreneurs take advantages of social media in marketing and operations by having a close and profitable relationship with peers, partners, and customers $[12,13]$. Since building a strong relationship is important for success, entrepreneurs tend to use social media to share information and find better opportunities. Entrepreneurs also try to expand their social networks and online communications to find new ideas. However, others are not taking advantage of social media for the same purposes of identifying opportunities or recruiting employees. It means that practitioners' perception of social media varies, from embracing potential benefits to being reluctant 
about the downsides. Moreover, the value of social media can be different for managers, entrepreneurs and customers [14]. Thus, social media use in marketing and entrepreneurship should be viewed holistically, with the firm's scope, culture, structure and governance taken into consideration [13]. For example, social media can be used to understand customers' views or feedback, but it can also be controlled and monitored by related parties such as stakeholders and partners.

In the same sense, it is questionable that the use of social media to empower entrepreneurial opportunity really works in practice. Regardless of the fundamental issue in entrepreneurship, there has been little exploration of what ability entrepreneurs need to achieve to identify entrepreneurial opportunities and whether social media impacts on the stages of creating a business. Therefore, the purpose of this study is to investigate the ways social media use impacts entrepreneurial opportunities. Based on social cognition theory, this study aims to explore factors that may impact two stages of the business-creation process: opportunity discovery and creation. This study will focus on the moderating role of social media use on entrepreneurial opportunities. By offering empirical research for nascent entrepreneurs, the results will suggest how and when to use social media to identify entrepreneurial opportunities.

\section{Theoretical Background}

\subsection{Social Cognitive Theory}

Social cognitive theory developed by Albert Bandura [15] provides a reciprocal causation model for expressing the psychological behaviors of individuals. The theory stresses that a continuous interaction between behavioral, cognitive and environmental factors determines the patterns of one's behavior $[16,17]$. Behavioral factors involve skill, practice and self-efficacy, which thereby influence one's thoughts and action. Cognitive factors, also called personal factors, involve prior knowledge, attitudes and expectations about outcomes. Environmental factors comprise culture and strategies, social norms, communications strategies and communities. Figure 1 shows the relationship of the three factors that determine human behaviors. The three factors do not need to have equal weight in causing these behavior patterns, but they are correlated to determine an individual's behavior.

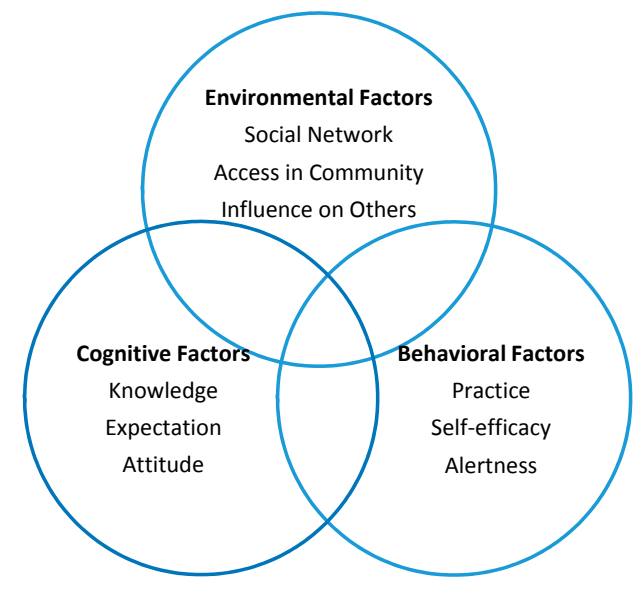

Figure 1. Three factors of social cognitive theory.

Social cognitive theory has been applied in many disciplines and widely used in studying aspects of business such as the organizational decision-making process, employees' behavior and technological innovation adoption $[18,19]$. Scholars argue that social cognitive theory is a useful framework for understanding human decision-making and behavior in a rapidly changing environment since it explains the complexities of human behavior from a broader perspective than other theories [20]. Social cognitive theory also emphasizes the process of an individual's behavior encouraging people to 
gain skills and knowledge in using new technology [19]. There are many media-related theories out there, e.g., uses and gratification theory. However, we believe that social cognitive theory would be the most suitable for examining entrepreneurs' behavior in discovering and creating entrepreneurial opportunities.

In this study, entrepreneurs' prior knowledge and experience in the market are considered as cognitive factors, while practices and foresight about market changes or customer needs are considered as behavioral factors. As cognitive factors, prior knowledge and social networks are known to determine the level of alertness. Individuals with higher levels of alertness tend to recognize entrepreneurial opportunities by connecting distinct ideas and knowledge. Prior knowledge and experience would also relate to the opportunity recognition process as a cognitive factor. Individuals with greater experience and knowledge will show a greater ability to sense and recognize opportunities since they have been put in a similar situation and accumulated knowledge on different opportunities. Previous research has also revealed that prior knowledge and experience play an important role in opportunity recognition [21,22].

As a behavioral factor, alertness plays an important role in recognizing entrepreneurial opportunities [23]. By constantly scanning the environment, entrepreneurs can identify new opportunities. Kirzner argued that alertness involves "creative and imaginative action" that influences the opportunity discovery in the future market [24] (p. 10). Environmental factors relate to the use of social media because they enable access to communities and make it easy for the entrepreneur to communicate with customers to gather information about the market. In early stage of entrepreneurship with dynamic open innovation, social network and communications are considered important components [25]. Additionally, social media used by individuals is related to opportunity recognition through an understanding of technology development, changes, and market trends [26].

Therefore, social cognitive theory can be used to explain the entrepreneur's behavior in finding a better opportunity that others have not seen. Since behavioral, environmental and cognitive factors do not make equal contributions to behavior, we investigate which factor will have more impact on discovering or creating opportunity. The result of this study supports the view of social cognitive theory that an individual's ability to discover and create entrepreneurial opportunity can be enhanced if given factors are encouraged.

\subsection{Entrepreneurial Opportunity}

Opportunity recognition is often referred as "the process by which entrepreneurs see something that has potential value" [27]. There are two conflicting views on opportunity recognition: the discovery and creation views of entrepreneurial opportunities. The debate over opportunity recognition has been largely conceptual in the extant literature. Many scholars have debated the disagreement between Kirzner [28] and Schumpeter's [29] views on entrepreneurial opportunity [30,31]. Kirzner's view is to access the various existing information in the marketplace, while Schumpeter's view is to access new information to recognize entrepreneurial opportunities. Kirzner argued that people discover opportunities not through search but through the recognition of the value of new information [28]. Discovering potentially lucrative entrepreneurial opportunities leads to an increase in profit by satisfying customer and market demands. Recognizing a new opportunity has a possibility of introducing innovative goods and services to a marketplace by either developing new products or significantly improving existing products [32]. Saravathy [33] also argues that fast-changing and uncertain market environment involve a number of potential opportunities that could result in future outcomes based on individuals' knowledge and alertness.

The discovery and creation view have distinct perspectives on opportunities, environment, resources, and cognition [2]. Opportunity discovery perspectives consider existing market conditions as a source of opportunity that drives entrepreneurial action and performance. In this perspective, opportunities are viewed as existing in the environment and as a fit between the resources 
of entrepreneurs and environmental changes in technology, consumer preferences, and market context $[34,35]$. It also takes a long time and involves a learning process to form an opportunity. Entrepreneurs can collect data and may use various data and information tools to discover the effective opportunity. Those who exploit a valuable discovery opportunity may generate a competitive advantage. However, the advantage can be temporary since the information about discovering opportunity can be easily accessible with social network and social media use [36].

On the other hand, creating opportunity is seen as the interaction of entrepreneurs with their environment [27]. That is, entrepreneurs take actions to form and exploit opportunities. Both perspectives may require different preparation and different predictions of entrepreneurs' actions to be effective. Opportunity created from technology and market changes may take the form of wealth creation, since the creation opportunity is costly to imitate [30]. However, the creation opportunity may result in ambiguous advantages depending on an individual's knowledge and experience and the market situation [37]. By contrast with the discovery perspective, the opportunity creation view suggests that opportunities do not exist unless they are created. This view focuses on perception and social enactment processes. Entrepreneurs act according to their own beliefs when responding to opportunities in the market. They then create opportunity based on their perceptions.

According to Shane and Venkataraman, business creation is a process of identifying the existence, discovery, and exploitation of opportunities [1]. Within this study, we seek to investigate two perspectives of entrepreneurial opportunity: the discovery and creation of entrepreneurial opportunities.

\section{Hypothesis Development}

Figure 2 shows a proposed research model representing the effect of three factors-knowledge, alertness and social media - on entrepreneurial opportunities. Hypotheses are developed based on the previous research to explain each relationship within the model.

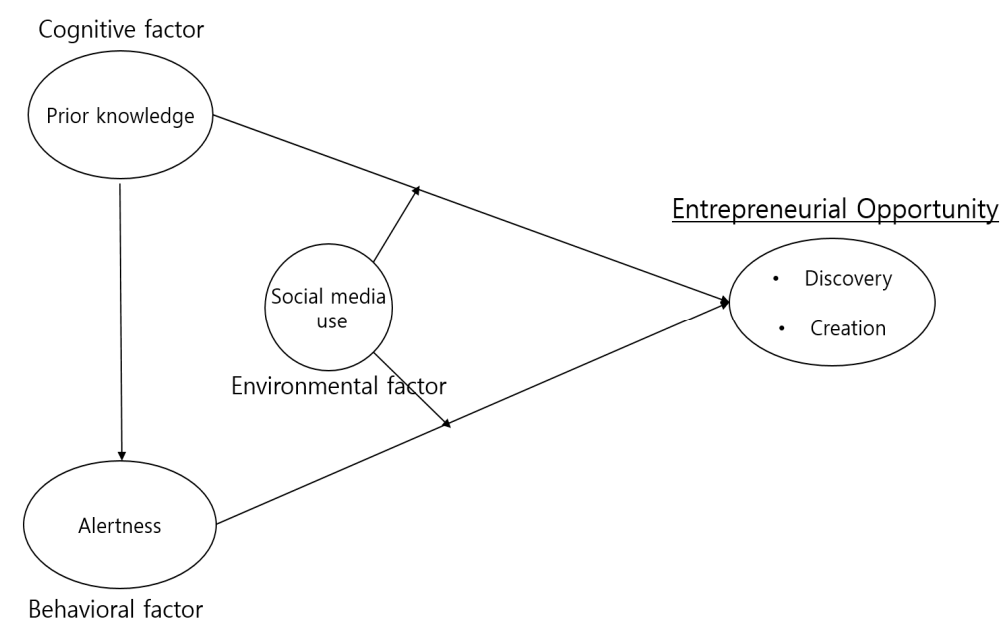

Figure 2. Proposed research model.

\subsection{Prior Knowledge (Cognitive Factor)}

Prior knowledge and knowledge-seeking behavior are the central factors of alertness. People who obtained knowledge from a social network and prior experience will have a better opportunity to find new markets than those who do not. Knowledge from business experience and management practice enhances alertness and enables the entrepreneur to identify a new opportunity. As with Schumpeter's view on alertness, such new information and new combinations can lead to opportunity recognition [26]. Politis [38] argues that experience and prior knowledge of the market can lead to a good customer relationship and influence new market-opportunity recognition. Entrepreneurs that 
have obtained substantial experience and prior knowledge are better able to analyze risk, cope with new things, and develop new products and services to meet customers' preferences [3].

Different types of prior knowledge will have an impact on identifying opportunities $[39,40]$. Shane and Venkataraman [1] illustrate that knowledge asymmetries play an important role in the process of discovering and creating entrepreneurial opportunities, and show that knowledge of the existing market and customers' problems will influence the alertness of entrepreneurial opportunities. They have classified three major dimensions of knowledge that influence alertness and market opportunities: knowledge of markets, knowledge of ways to serve markets and knowledge of customer problems. Craig and Johnson [23] showed that individuals differ in recognizing entrepreneurial opportunity from their academic training. They found that individuals with business training were more proficient at recognizing opportunities than respondents trained in engineering. Siegel and Renko [26] also revealed that both technological knowledge and market knowledge contribute to firms' recognition of entrepreneurial opportunities. Overall, an individual with knowledge through education and experience will be more likely than other people to discover entrepreneurial opportunities.

Hypothesis 1-1 (H1-1). Prior knowledge is positively related to the discovery of entrepreneurial opportunity.

Hypothesis 1-2 (H1-2). Prior knowledge is positively related to the creation of entrepreneurial opportunity.

People are alert because they have access to knowledge that is distributed asymmetrically and they possesses different information and different perspectives $[1,28]$. That is, prior knowledge fosters people's alertness to entrepreneurial opportunities. According to Baron [21], the individual's ability to recognize patterns in complex economic events varies. Moreover, the individual's knowledge influences their interpretation of events and opportunities [26]. That means individual knowledge can impact on alertness to entrepreneurial opportunities. Such different knowledge and cognition factors influence individuals' alertness, and that could explain why a person might recognize opportunities that others cannot. Therefore, prior knowledge that people possess could make them better able to scan, connect, and judge information that will help them discover and create entrepreneurial opportunities.

Hypothesis 2 (H2). Prior knowledge is positively related to entrepreneurial alertness.

\subsection{Entrepreneurial Alertness (Behavioral Factor)}

Alertness has been studied by many scholars in the entrepreneurship field where opportunity recognition is a crucial process in creating a firm. Entrepreneurial alertness is defined as "the ability to notice without search opportunities that have been overlooked" and "the sense to notice that which has not been suspected of existing at all" [24,28]. The current view is that alertness emerges from environmental, market, and technological changes [41]. Entrepreneurial alertness involves scanning and searching for new information and changes in the market environment [35]. These elements of entrepreneurial alertness are a part of the cognition process that is influenced by cognitive capacities such as prior knowledge, experience and pattern recognition.

Alertness is acknowledged as a primary factor in opportunity identification [42]. It is through this process that entrepreneurs assess market changes to identify potential entrepreneurial opportunities. Entrepreneurial alertness impacts the ability to find and create new opportunities, which in turn, enhances performance and innovativeness. Tang et al. [35] classified alertness in terms of three distinctive dimensions such as scanning and searching, association and connection, and evaluation and judgment. Some argue that entrepreneurial alertness involves the action of moving toward the creation and possibility for opportunities [43]. The behavioral action of evaluation and judgement of alertness reflects the effort needed to find an opportunity that possesses profit or beneficial chances. 
Venkataraman [40] claimed that awareness of entrepreneurial opportunities is a significantly different matter from creating and exploiting the opportunities. Discovery depends on relative differences between people in their willingness and ability to search for and identify opportunities [1]. Jiao et al. [44] explored the positive relationship between alertness and innovation with an empirical analysis. Schumpeter's asserted opportunities are created by an innovative entrepreneur by accessing new information and recombining resources [31]. Moreover, the relationship between sales person opportunity recognition and the performance of individual salespeople is affected by the presence of awareness, discovery, and evaluation. Corbett [7] asserted that people have to build the capability of transferring and judging the information and knowledge that they acquire, and Fiet [45] posited that a combination of one's prior knowledge and experience are the basis of opportunity discovery. Accordingly, a person's entrepreneurial alertness can influence their ability to create entrepreneurial opportunities.

Hypothesis 3-1 (H3-1). The entrepreneurial alertness is positively related to the discovery of entrepreneurial opportunity.

Hypothesis 3-2 (H3-2). The entrepreneurial alertness is positively related to the creation of entrepreneurial opportunity.

\subsection{Social Media Use (Environmental Factor)}

Using advanced technology and social network services can change market trends and create new information. Social media technology can easily combine various source of information and create new combinations that provide new information. Researchers have revealed that knowledge obtained from social networks helps people to gain new information and seize new opportunities [46]. According to McKelvie and Wiklund [47], determining the market value of new technological changes has a positive effect on opportunity recognition. They also argued that increased communication in new technology between user and customer is important to discover entrepreneurial opportunities.

People who actively use social media should get more information and better combine and transform the information acquired. Social media can raise the awareness of market changes and customer behavior, and act as a trigger for creating an opportunity that meets customer demands. Kolb [48] explained that the acquired information can be transformed and combined with prior knowledge through socializing, allowing individuals to search for the best information and avoid errors so they can identify as many chances as possible. In this process, social media use is the most effective tool for combining, comparing and evaluating information for entrepreneurial opportunities. Young start-ups and entrepreneurs who begin their business with limited knowledge and resources are heavily influenced by social media and sense trends and opportunities. Therefore, the hypotheses are as follows:

Hypothesis 4-1 (H4-1). Social media use positively moderate the relationship between prior knowledge and the discovery of entrepreneurial opportunity.

Hypothesis 4-2 (H4-2). Social media use positively moderate the relationship between prior knowledge and the creation of entrepreneurial opportunity.

Hypothesis 4-3 (H4-3). Social media use positively moderate the relationship between entrepreneurial alertness and the discovery of entrepreneurial opportunity.

Hypothesis 4-4 (H4-4). Social media use positively moderate the relationship between entrepreneurial alertness and the creation of entrepreneurial opportunity. 


\section{Methodology}

\subsection{Participants and Data Collection}

Data was collected from entrepreneurs who have created their own company and employees who work in entrepreneurial companies. Since opportunity discovery and creation are strategically important in entrepreneurship, these constructs are appropriate to our study for the measurement of social media effects. We collected survey questionnaires from entrepreneurs working in business incubation centers. The business incubation centers in universities provide entrepreneurs not only business space, but related support such as education and mentoring to help them establish a business. Respondents were mostly CEOs or team leaders in entrepreneurial firms under 5 years of age. They usually had creative business ideas and technologies, but seldom had the ability to commercialize them. These characteristics of our sample were well suited to our study in the sense that identifying entrepreneurial opportunities was a fundamental issue for them and thus they were likely to use social media a lot in order to access information and search out new opportunities. The demographic characteristics of the participants in the sample are shown in Table 1.

Table 1. Summary of demographic characteristics.

\begin{tabular}{cccc}
\hline & & Frequency & Percentage \\
\hline Gender & male & 142 & 80.2 \\
& female & 35 & 19.7 \\
Age & $<25$ & 13 & 7.3 \\
& $25-30$ & 67 & 37.9 \\
& $31-40$ & 46 & 26 \\
& $41-50$ & 32 & 18.1 \\
Position & $>51$ & 19 & 10.7 \\
& CEO & 112 & 63.3 \\
& Team Leader & 46 & 26 \\
& employees & 19 & 10.7 \\
\multirow{4}{*}{ Firm-age } & IT-related & 99 & 55.9 \\
& non IT & 78 & 44.1 \\
& related & 86 & 48.6 \\
& $<1$ year & 71 & 40.1 \\
& 2-3 years & 12 & 6.8 \\
Sum & 4-5 years & 8 & 4.5 \\
& $>5$ years & 177 & 100 \\
\hline
\end{tabular}

As the goal of this study was to investigate the entrepreneurs' behavior with self-reported survey items, there might be some concern about the existence of common method variance (CMV). To minimize CMV, we utilized the following procedures. First, we protected the respondents' anonymity. Second, we pre-tested survey questionnaires to reduce ambiguity. In addition, we separated those questions pertaining to independent variables and dependent variables [49]. Survey items were developed and adopted from previous research, and all items were measured with a 7-point Likert scale (see Table A1). Interviewers familiar with this study and trained to elicit answers administered the survey. In total, data from 201 participants was collected. After eliminating samples with bias and missing data such as identical answers and blanks, we used 177 responses in the empirical analysis showing $88 \%$ of response rates.

\subsection{Measure of Constructions}

This study examined the factors influencing entrepreneurial opportunities: prior knowledge, alertness, and social media. The definitions of constructs and measurement items used were adopted from previous research and are described as follows: 
Prior knowledge was considered to be an individual's experience or education that influence their ability to comprehend customer problems, market characteristics and ways to serve markets. Shane [22] argued that the three major dimensions of prior knowledge are important to opportunity discovery. With this in mind, we asked entrepreneurs about their knowledge of the market, customer problems, and market sales. We also asked entrepreneurs about the extent of their experience in the industry to measure prior knowledge.

Entrepreneurial alertness referred to the capacity to recognize changes in technology, markets, and competition, and was assessed using the alertness scale provided by Tang et al. [35]. Tang's alertness scale consists of items including three elements: scanning and search, association and connection, evaluation and judgement. Scanning and search involves preparedness and sensitivity to new opportunities; association and connection involves pulling distinct information together to sense new opportunities; and evaluation and judgement involves deciding whether to act on these opportunities based on value in future markets.

Social media use was measured by the degree to which entrepreneurs were using social media in their work and perceived it to be useful [50]. Questionnaires included "I often use social media to obtain work related information and knowledge", and "Using social media (e.g., Facebook, blogs) for work is effective".

Entrepreneurial opportunity referred to the process by which entrepreneurs seek out or create the "something" that provides potential market value and benefits. Entrepreneurial opportunities were measured in two dimensions as opportunity discovery and creation. Opportunity discovery is the perception of recognizing and identifying business opportunities that relies on an individual's knowledge and sense of market changes; while opportunity creation involves the perception of developing and reframing opportunities through new ideas about the market. Adopting questionnaires by Craig and Johnson [23], respondents were asked whether they are likely to discover entrepreneurial opportunities in the existing market with known information, or develop new ideas and products to find new ways of doing things in the market.

\section{Result}

\subsection{Measurement Analysis}

The partial least squares (PLS) method was used to access the measurement and structural analysis of our research model. PLS has become popular in entrepreneurship and management research. Since this study was exploratory and the research predictive, PLS was well suited for analyzing our model. In this study, the Smart PLS 2.0 software developed by Ringle et al. [51] was used to conduct the analysis.

The validity of the measurement scale was determined by examining its internal consistency and the convergent and discriminate validities. As seen in Table 2, values for each variable satisfied the recommended threshold level, which was above 0.7 [52]. We, therefore, concluded that the items were reliable. Convergent validity was checked by examining whether the average variance extracted (AVE) values were greater than 0.5 and the square roots of the AVE values were higher than their corresponding correlations [53]. All constructs in this study met the requirement. To test the discriminate validity, the square root of the AVE values for each construct should be greater than 0.7 and higher than the off-diagonal correlations [52]. In Table 2, the diagonal values represent the square roots of the AVE values, all of which were greater than 0.7 , and their corresponding correlation coefficients. This confirms that all variables used in this study met the recommended criteria for validity.

Moreover, to test the multicollinearity issue, the value of tolerance and variance inflation factor (VIF) were examined. Tolerance greater than 0.1 and VIF less than 10 are recommended [54]. Thus, the independent variables in this study were not considered to present a collinearity problem. 
Table 2. Internal consistency and discriminant validity.

\begin{tabular}{lccccccccc}
\hline & \multirow{2}{*}{ Internal Consistency } & \multirow{2}{*}{ AVE } & \multicolumn{4}{c}{ Correlation of Constructs } & \multicolumn{2}{c}{ Collinearity Statistics } \\
\cline { 4 - 10 } & & & $\mathbf{1}$ & $\mathbf{2}$ & $\mathbf{3}$ & $\mathbf{4}$ & $\mathbf{5}$ & Tolerance & VIF \\
\hline 1. Prior KW & 0.825 & 0.756 & $\mathbf{0 . 9}$ & & & & & 0.484 & 2.068 \\
2. Alertness & 0.906 & 0.829 & 0.68 & $\mathbf{0 . 9 1}$ & & & & 0.471 & 2.123 \\
3. Social Media & 0.852 & 0.792 & 0.26 & 0.24 & $\mathbf{0 . 8 7}$ & & & 0.902 & 1.109 \\
4. Discovery & 0.946 & 0.892 & 0.79 & 0.73 & 0.26 & $\mathbf{0 . 9 4}$ & & & \\
5. Creation & 0.846 & 0.898 & 0.67 & 0.69 & 0.24 & 0.71 & $\mathbf{0 . 9 5}$ & & \\
\hline
\end{tabular}

\subsection{Structural Analysis}

The proposed hypotheses were tested by assessing the structural model. The structural model was assessed by examining the significance of the relationships among variables with path coefficients and the explanatory power of the variables with the $R^{2}$ value. PLS provided the bootstrap resampling method for determining the significance of path coefficients [53].

Table 3 reports the path coefficients and the significance of each path ( $t$-statistic value). The results showed that prior knowledge and alertness were positively related to both opportunity discovery and creation. Prior knowledge also showed a positive effect on alertness as described in prior research [22]. However, the moderating effect of online social media usage was somewhat different. Social media usage negatively moderated the relationship between prior knowledge and the discovery of entrepreneurial opportunity (path coefficient $=-0.16, p<0.01$ ) while its moderating effects showed no significance on the creation of entrepreneurial opportunity. Therefore, contrary to our expectations, the positive effects of social media usage on the prior knowledge and opportunity discovery/creation relationship meant that, H4-1 and H4-2 were not supported. However, we note here that the negative moderating effect of social media on the discovery of entrepreneurial opportunity would imply different aspects of social media use in entrepreneurship. That is, the information from social media may hinder an entrepreneur's ability to find opportunity based on prior knowledge. Further analysis and discussion about this result is described in the following section.

Table 3. The result of structural analysis.

\begin{tabular}{|c|c|c|c|c|c|}
\hline & From & To & Path Coefficient & $t$-Value & Sig. \\
\hline H1-1 & Prior KW & discovery & 0.515 & 8.274 & $* *$ \\
\hline H1-2 & Prior KW & creation & 0.315 & 4.334 & ** \\
\hline H1-3 & Prior KW & alertness & 0.67 & 11.478 & $* *$ \\
\hline $\mathrm{H} 2-1$ & Alertness & discovery & 0.36 & 5.63 & $* *$ \\
\hline $\mathrm{H} 2-2$ & Alertness & creation & 0.44 & 5.118 & $* *$ \\
\hline H3-1 & Prior $\mathrm{KW}$ *social media & discovery & -0.160 & 1.947 & * \\
\hline H3-2 & Prior KW *social media & creation & -0.245 & 1.444 & \\
\hline H3-3 & Alertness *social media & discovery & 0.085 & 1.074 & \\
\hline H3-4 & Alertness *social media & creation & 0.367 & 2.269 & $* *$ \\
\hline
\end{tabular}

Regarding the creation of entrepreneurial opportunity, the results showed that social media usage has a positive moderating effect on the relationship between entrepreneurial alertness and opportunity creation (path coefficient $=0.367, p<0.01$ ), supporting H4-4. $R^{2}$ on discovery and creation is 0.71 , 0.64 respectively showing that the explanation power of these variables was $71 \%$ and $64 \%$ on this model. Performance on this model showed $24 \%$ of explanatory power.

\section{Discussion}

Social media have been reported to have disruptive effects on business by providing knowledge integration, low-cost information disclosure, and wide network systems [55,56]. Social media increases knowledge integration within and outside firm boundaries. Such knowledge integration and idea collaboration would trigger the creation of new opportunities and change the way businesses operate, 
which may lead to achieving a competitive advantage. Social media also accelerates decision-making processes and information development [57]. However, interestingly, the impacts of social media on entrepreneurial opportunities in our study show somewhat different results from those in previous research. Contrary to our hypothesis, the social media usage negatively moderated the relationship between prior knowledge and the discovery of entrepreneurial opportunity. In order to understand this contrast with previous research and our proposed hypothesis, we conducted post hoc interviews with four people, three of whom were entrepreneurs running their own startup companies and one a coordinator in a venture incubation center. The types of products and services they provide varied from a tourist guide application for smartphones to a user interface framework. Questions were asked of entrepreneurs about how they gather information from social media, how credible they feel social media information is, what values they place on social media information, and to what extent they rely on social media information for their business ideas and opportunities. Table 4 summarizes the perception of social media information and usage from the post hoc interviewees.

Table 4. Post hoc interview analysis.

\begin{tabular}{|c|c|c|c|c|}
\hline & Case A & Case B & Case C & Case D \\
\hline $\begin{array}{l}\text { Major sources of } \\
\text { information for } \\
\text { business } \\
\text { development }\end{array}$ & Peers and coworkers & $\begin{array}{c}\text { Social media, } \\
\text { conference, } \\
\text { customer contact }\end{array}$ & $\begin{array}{l}\text { Coworkers, peers, } \\
\text { personal relationship }\end{array}$ & \\
\hline $\begin{array}{l}\text { Credibility of } \\
\text { social media } \\
\text { information }\end{array}$ & Low & Medium & Medium & Low \\
\hline $\begin{array}{l}\text { How they use } \\
\text { information from } \\
\text { social media }\end{array}$ & $\begin{array}{l}\text { To search up-to-date } \\
\text { information }\end{array}$ & $\begin{array}{l}\text { To understand } \\
\text { market trends and } \\
\text { customer feedback }\end{array}$ & $\begin{array}{c}\text { To discover drawbacks } \\
\text { of products }\end{array}$ & $\begin{array}{l}\text { Often to } \\
\text { understand market } \\
\text { trends and changes, } \\
\text { gather customer } \\
\text { feedback and } \\
\text { information }\end{array}$ \\
\hline $\begin{array}{l}\text { Dependency on } \\
\text { social media } \\
\text { information }\end{array}$ & Low & Low & Low & Low \\
\hline $\begin{array}{c}\text { Source of } \\
\text { business idea }\end{array}$ & $\begin{array}{c}\text { Prior } \\
\text { experience/knowledge }\end{array}$ & Prior experience & $\begin{array}{c}\text { Prior } \\
\text { experience/knowledge }\end{array}$ & \\
\hline Comments & $\begin{array}{l}\text { "The reason I start a } \\
\text { company is to find the } \\
\text { way to improve the } \\
\text { function of a device I } \\
\text { have used. That means } \\
\text { my business idea came } \\
\text { up with my own } \\
\text { experience of using the } \\
\text { product", } \\
\text { "I do not rely on social } \\
\text { media information } \\
\text { since there is lots of } \\
\text { uncertain and } \\
\text { untrustworthy } \\
\text { information" }\end{array}$ & $\begin{array}{l}\text { "We frequently } \\
\text { check social media } \\
\text { information and } \\
\text { communication to } \\
\text { figure out a } \\
\text { customer's } \\
\text { feedback and new } \\
\text { information in } \\
\text { tourism", } \\
\text { "Our business } \\
\text { model stems from } \\
\text { prior experience } \\
\text { using a tourist } \\
\text { guide application" }\end{array}$ & $\begin{array}{l}\text { "I have been interested } \\
\text { in user interface } \\
\text { development since I } \\
\text { have done various } \\
\text { exercises in an } \\
\text { IT-related field for a } \\
\text { substantial time" “... } \\
\text { entrepreneurial } \\
\text { decisions are not made } \\
\text { by social media } \\
\text { information ..." }\end{array}$ & $\begin{array}{c}\text { "Nascent } \\
\text { entrepreneurs who } \\
\text { are short of social } \\
\text { capital may rely on } \\
\text { social media } \\
\text { information to } \\
\text { expand a social } \\
\text { network and } \\
\text { gather needed } \\
\text { information. } \\
\text { However, actual } \\
\text { decisions on } \\
\text { entrepreneurial } \\
\text { opportunity are } \\
\text { made based on } \\
\text { their knowledge } \\
\text { and insight taken } \\
\text { from prior } \\
\text { experiences." }\end{array}$ \\
\hline
\end{tabular}

Unlike traditional business environments where social media offers great opportunity, especially in sensing market trends, the effects of social media in entrepreneurship may have different consequences. All interviewees mentioned that they rely more on relevant experiences and knowledge than information received from various online social media. They said that social media is often used to understand up-to-date information and market trends, but not used to decide business ideas or 
create a business. Rather, they emphasized the value of their experiences and knowledge taken from previous companies or personal relationships for accessing business opportunities for their start-up decision. Entrepreneurs who create new start-ups also stress prior knowledge and experience in a similar industry as follows.

“... it can be dangerous to rely on untrustworthy and unreliable information from social media. I rather believe in my knowledge and rely on my past experience to find a new opportunity for a start-up..."

"... too much information online could distract me from making good decisions about new opportunities..."

"... my prior knowledge and experience in a similar business environment help me discovering new opportunities and developing a start-up ..."

This is consistent with opportunity discovery and creation theories such as path dependence. That is, the past existing path such as prior knowledge results in exploration and exploitation of entrepreneurial opportunities for any given circumstances [36]. For discovery theory, prior knowledge and past experience influence decisions about whether to combine information and discover new opportunities that lead to entrepreneurs' actions. For creation theory, the path can be the result of actions that entrepreneurs use to form an opportunity. Here, entrepreneurs explore an opportunity to build foundational conditions as a blueprint for an initial form of start-up and subsequent growth.

As our empirical findings showed, information received from social media may negatively effect on the discovery of entrepreneurial opportunity based on previous knowledge and experience. That is, entrepreneurs who lack prior knowledge and experience would rely more on social media information for their decision-making about opportunities, while entrepreneurs with sufficient knowledge would be reluctant to use social media information for creating a business. This post hoc interview implies that the practical use of social media can be different from the theoretical studies by showing that there is skepticism about the value of social media in strategic decision-making among startups. They feel low confidence in social media information that they see as having less value, so in turn, social media use may not help them find entrepreneurial opportunities. Consistent with the empirical results of Porter et al. [58], that social media sources are least trustworthy and personal contacts most trustworthy, our post hoc interview shows that when it comes to social media credibility interviewees think its reliability is quite low. They believe knowledge from personal contacts and experiences are the most reliable sources to use when deciding on entrepreneurial opportunities. They mentioned that social media information is useful for understanding market trends and customers' feedback, but unreliable when making a certain decision on entrepreneurial opportunities. A possible explanation can be that since there is a lot at stake for entrepreneurs, due to a great number of uncertain opportunities in a new market, they tend to behave more discreetly when using social media information.

Social media use is beneficial in various ways that are consistent with the evidence of its effectiveness claimed in previous research studies [59]. As shown in our study, social media use works better to create new opportunities once an entrepreneur obtains a higher level of entrepreneurial alertness. In other words, entrepreneurs obtaining a higher sense of alertness are likely to assess market changes to identify potential entrepreneurial opportunities using social media. Because the opportunities are created by accessing new information and recombining resources, an innovative entrepreneur with entrepreneurial alertness takes great advantage of social media in scanning and searching, and connecting information in the markets.

The benefits of social media have been proven empirically in many studies, and it continues to offer considerable promise [60]. However, it seems that the use of social media in practice, especially in strategic decisions related to entrepreneurial opportunity, remains uncertain both in terms of the value of social media and in the credibility of the information it provides. This also implies that entrepreneurs do not have sufficient understanding about the strategic use of social media in the entrepreneurial process. Since some people using social media may tend to behave without reflection or rational 
thought, people are sometimes skeptical about the value of social media [61]. Thus, it is important to understand how much trust and confidence entrepreneurs should place on information found online on social media platforms.

\section{Conclusions and Implication}

This study aims to clarify the importance of prior knowledge, alertness and social media in identifying entrepreneurial opportunities and their contribution to the success of entrepreneurs. Based on the social cognitive theory, entrepreneurial opportunity recognition can be influenced by cognitive, environmental and behavioral factors: prior knowledge, social media use, and entrepreneurial alertness. These factors determined the extent of the influence on opportunity recognition and performance in this study. Prior knowledge and entrepreneurial alertness were strongly affected by both entrepreneurial discovery and creation, while the moderating effect of social media was shown to be positive with alertness to opportunity creation and negative with prior knowledge of opportunity discovery.

Prior knowledge and experience recognizing opportunity and forecasting performance were shown to be important factors for entrepreneurs who create new businesses. This finding is consistent with prior research showing prior knowledge and experience play an important role in business evaluation and entrepreneurial judgment [62]. Entrepreneurial alertness can also play a role in identifying opportunities and creating a new business with great accuracy and less bias in forecasting expectations. These findings appear to diverge from previous research in that they suggest important practical and academic implications regarding what abilities entrepreneurs need in order to identify new opportunities and create a business. It is suggested that novice entrepreneurs with limited entrepreneurial experience and business knowledge should work with experienced entrepreneurs to study their cognitive patterns to recognize opportunities and convert it to performance. Moreover, entrepreneurial alertness, which is a sense of capturing changes in the market, can be improved by keeping up-to-date on information, reading newspaper articles, and staying aware of the latest trends.

This study also diverged from other research in that it examined whether social media was used to provide better opportunities for entrepreneurs, and whether it really works in discovering and creating opportunities. This study showed that the advances of social media in practice remain based on the users' perceptions and enthusiasm about its implementation. As our research shows, the more social media use, the less the effect of prior knowledge on opportunity finding and creation. Additionally, the interview with novice entrepreneurs suggested that knowledge found in social networks does not have a greater impact on opportunity recognition and business creation than the experience and knowledge entrepreneurs possess. In other words, entrepreneurs who try to capture new ideas and opportunities for business creation would not be disturbed by social media users. These findings related to entrepreneurs' social media use upon entrepreneurial opportunity recognition could provide the following implications.

First, social media use could hinder the entrepreneurs' ability to recognize opportunities that lead to starting a business. Social media can facilitate communication and the decision-making process, but could result in a lack of socialization in practice. The ability to recognize a hidden and unknown opportunity may come from experience and practice. Second, social media could muddle prior planning and a business model built upon the entrepreneur's own experience and knowledge. Social media can bring people information that can help them find new opportunities and business. However, random people and information in the online space could mean sharing common information and selling a commodity in a way that is no better than the specialized knowledge and experience of the entrepreneur. Moreover, there are countless anonymous individuals on social media platforms producing inaccurate and untrustworthy information, which means it is not always possible for an entrepreneur to identify the best opportunities for their business. This overwhelming volume of information results in wasted time and effort trying to identify business opportunities. Therefore, when discovering an opportunity related to targeting business, entrepreneurs should use their own sense and expertise in finding entrepreneurial opportunities and making decisions about whether 
to provide new products and services. To sum up, the value of this research lies in focusing on the factors influencing entrepreneurial opportunity and the effect of social media on its relationship with entrepreneurs. This research makes an important contribution to the existing literature on social media and entrepreneurial opportunity, and has implications for further research and practice in entrepreneurship and related fields.

Despite the contributions of this study, it had a couple of limitations. We suggest future research as follows: first, the sample of this study was only focused on the early stage of entrepreneurship. In future research, the sample should include a range of entrepreneurs in industries, the number years they have worked, and the purpose of their entrepreneurship. It would be of interest to examine the differences among entrepreneurs in their use of new technology for entrepreneurial opportunities. Second, although this study adopted social cognitive theory to investigate entrepreneurs' behavior in identifying opportunities, there might be other media-related theories that can also apply. In future research, it would make sense to apply other theories to investigating why entrepreneurs use social media and what gratification can be fulfilled when creating business.

Acknowledgments: This paper was recommended to the special issue "Sustainability of Economy Growth-New Combination of Technology, Market and Society" at SOItmC2017. This paper was improved by constructive reviews and comments at the conference and during the reviewing process. We appreciate anonymous reviewers and editors for their thoughtful comments.

Author Contributions: Joo Y. Park conceived and designed the research and wrote the paper; Chang Soo Sung performed the survey and interview for data analysis; II Im contributed to modifying and reviewing the paper

Conflicts of Interest: The authors declare no conflict of interest. The founding sponsors had no role in the design of the study; in the collection, analyses, or interpretation of data; in the writing of the manuscript, and in the decision to publish the results.

\section{Appendix A}

Table A1. Survey items and sources.

\begin{tabular}{|c|c|}
\hline Items & Sources \\
\hline $\begin{array}{l}\text { Prior knowledge } \\
\text { I know how to serve the market } \\
\text { I am familiar with customer problems } \\
\text { I have rich knowledge about markets such as supplier relationships, sales technique, capital } \\
\text { equipment requirements, etc } \\
\text { My experience starting a new business helps me to gain lots of knowledge } \\
\text { My industrial experience helps me to gain lots of knowledge } \\
\text { My experience as a member of a high-level management team helps me to gain lots of knowledge }\end{array}$ & [63] \\
\hline $\begin{array}{l}\text { Social media use } \\
\text { I often use social media to obtain work-related information and knowledge } \\
\text { I regularly use social media to maintain and strengthen communication with colleges in my work } \\
\text { I can gain lots of knowledge from contact/customers in social network systems } \\
\text { I use social media to contact customers } \\
\text { I can gain lots of knowledge from contacts/customers in social network systems. }\end{array}$ & {$[50,64]$} \\
\hline $\begin{array}{l}\text { Alertness to business ideas } \\
\text { I always have ideas for new business } \\
\text { While going about day-to-day activities, I still explore new business ideas } \\
\text { I always keep an eye out for new business ideas when looking at information } \\
\text { I have special sensitivity toward new business ideas } \\
\text { I have frequent interactions with others to acquire new information. } \\
\text { I always keep an eye out for new business ideas when looking for information. }\end{array}$ & [35] \\
\hline $\begin{array}{l}\text { Opportunity discovery } \\
\text { I discover entrepreneurial opportunities that exist in my industry. } \\
\text { I discover previously unnoticed entrepreneurial opportunities. } \\
\text { I am excited by the knowledge that there are many unexploited entrepreneurial opportunities } \\
\text { I undertake methods and solutions to product problems that build on my experience } \\
\text { I searched for product information and ideas that took the firm into existing product areas }\end{array}$ & [23] \\
\hline $\begin{array}{l}\text { Opportunity creation } \\
\text { I am attracted by the idea of breaking away from routine activity } \\
\text { I like to discover new ways of doing things } \\
\text { I prefer to find new uses for existing products } \\
\text { I am a source of innovative ideas } \\
\text { I collect information on totally new products } \\
\text { I search for product information involving experimentation and high risk }\end{array}$ & [23] \\
\hline
\end{tabular}




\section{References}

1. Shane, S.; Venkataraman, S. The promise of entrepreneurship as a field of research. Acad. Manag. Rev. 2000, 25, 217-226. [CrossRef]

2. Alvarez, S.A.; Barney, J.B.; Anderson, P. Forming and Exploiting Opportunities: The Implications of Discovery and Creation Processes for Entrepreneurial and Organizational Research. Org. Sci. 2013, 24, 301-317. [CrossRef]

3. Li, Y.; Wang, P.; Liang, Y.-J. Influence of entrepreneurial experience, alertness and prior knowledge on opportunity recognition. Soc. Behav. Personal. 2015, 43, 1575-1584. [CrossRef]

4. Nieto, M.; Gonzalez-Alvarez, N. Social capital effects on the discovery and exploitation of entrepreneurial opportunities. Int. Entrep. Manag. J. 2016, 12, 507-530. [CrossRef]

5. Short, J.C.; Ketchen, D.J., Jr.; Shook, C.L.; Ireland, R.D. The concept of opportunity in entrepreneurship research: Past accomplishments and future challenges. J. Manag. 2010, 36, 40-65. [CrossRef]

6. Sitkin, S.B.; Pablo, A.L. Reconceptualizing the determinants of risk behaviour. Acad. Manag. Rev. 1992, 17, 9-38.

7. Corbett, A.C. Learning asymmetries and the discovery of entrepreneurial opportunities. J. Bus. Ventur. 2007, 22, 97-118. [CrossRef]

8. Krueger, N.J.; Dickson, P.R. How believing in ourselves increases risk taking: Perceived self-efficacy and opportunity recognition. Decis. Sci. 1994, 25, 385-400. [CrossRef]

9. Cohen, B.; Winn, M.I. Market imperfections, opportunity and sustainable entrepreneurship. J. Bus. Ventur. 2007, 22, 29-49. [CrossRef]

10. De Carolis, D.M.; Saparito, P. Social capital, cognition, and entrepreneurial opportunities: A theoretical framework. Entrep. Theory Pract. 2006, 1, 41-56. [CrossRef]

11. Lim, W.L.; Xavier, S.R. Opportunity Recognition Framework: Exploring the Technology Entrepreneurs. Am. J. Eco. 2015, 5, 105-111.

12. Cort, V.D.; Lavazzi, A.; D'Andrea, C. Customer involvement through social media: The cases of some telecommunications firms. J. Open Innov. Technol. Mark. Complex. 2015, 1, 10. [CrossRef]

13. Felix, R.; Rauschnabel, P.A.; Hinsch, C. Elements of strategic social media marketing: A holistic framework. J. Bus. Res. 2017, 70, 118-126. [CrossRef]

14. Rokka, J.; Karlsson, K.; Tienari, J. Balancing acts: Managing employees and reputation in social media. J. Mark. Manag. 2014, 30, 802-827. [CrossRef]

15. Bandura, A. Social cognitive theory: An agentic perspective. Annu. Rev. Psychol. 2001, 52, 1-26. [CrossRef] [PubMed]

16. Bandura, A. Social Foundations of Thought and Action: A Social Cognitive Theory; Prentice-Hall: Englewood Cliffs, NJ, USA, 1986.

17. McCormick, M.J.; Martinko, M.J. Identifying leader social cognitions: Integrating the causal reasoning perspective into social cognitive theory. J. Leadersh. Org. Stud. 2004, 10, 2-11. [CrossRef]

18. Chan, S.; Lu, M. Understanding internet banking adoption and use behavior: A Hong Kong perspective. J. Glob. Inf. Manag. 2004, 12, 21-43. [CrossRef]

19. Compeau, D.; Higgins, C.; Huff, S. Social cognitive theory and individual reactions to computing technology: A longitudinal study. MIS Q. 1999, 23, 145-158. [CrossRef]

20. Davis, T.R.V.; Luthans, F. A social learning approach to organizational behavior. Acad. Manag. Rev. 1980, 5, 281-290.

21. Baron, R.A. Opportunity recognition as pattern recognition: How entrepreneurs "connect the dots" to identify new business opportunities. Acad. Manag. Perspect. 2006, 20, 104-119. [CrossRef]

22. Shane, S. Prior knowledge and the discovery of entrepreneurial opportunities. Org. Sci. 2000, 11, 448-469. [CrossRef]

23. Craig, J.B.L.; Johnson, D. Establishing individual differences related to opportunity alertness and innovation dependent on academic-career training. J. Manag. Dev. 2006, 25, 28-39. [CrossRef]

24. Kirzner, I.M. Creativity and/or alertness: A reconsideration of the Schumpeterian entrepreneur. Rev. Austrian Econ. 1999, 11, 5-17. [CrossRef] 
25. Yun, J.H.; Won, D.K.; Park, K. Dynamics from open innovation to evolutionary change. J. Open Innov. Technol. Mark. Complex. 2016. Available online: https://doi.org/10.1186/s40852-016-0033-0 (accessed on 7 September 2017).

26. Siegel, D.S.; Renko, M. The role of market and technological knowledge in recognizing entrepreneurial opportunities. Manag. Decis. 2012, 50,797-816. [CrossRef]

27. Ardichvili, A.; Cardozo, R.; Ray, S. A theory of entrepreneurial opportunity identification and development. J. Bus. Ventur. 2003, 18, 105-123. [CrossRef]

28. Kirzner, I.M. Entrepreneurial discovery and the competitive market process. An Austrian approach. J. Econ. Lit. 1997, 35, 60-85.

29. Schumpeter, J.A. The Theory of Economic Development; Transaction Publishers: London, UK, 1934.

30. Barney, J. Firm resources and sustained competitive advantage. J. Manag. 1991, 17, 99-120. [CrossRef]

31. Buenstorf, G. Creation and pursuit of entrepreneurial opportunities: An evolutionary economics perspective. Small Bus. Econ. 2007, 28, 323-337. [CrossRef]

32. Gaglio, C.M. The role of mental simulations and counterfactual thinking in the opportunity identification process. Entrep. Theory Pract. 2004, 28, 533-552. [CrossRef]

33. Sarasvathy, S.D. Causation and effectuation: Toward a theoretical shift from economic inevitability to entrepreneurial contingency. Acad. Manag. Rev. 2001, 26, 243-263.

34. Edelman, L.; Yli-Renko, H. The Impact of Environment and Entrepreneurial Perceptions on Venture-Creation Efforts: Bridging the Discovery and Creation Views of Entrepreneurship. Entrep. Theory Pract. 2010, 34, 833-856. [CrossRef]

35. Tang, J.; Kacmar, K.M.; Busenitz, L. Entrepreneurial alertness in the pursuit of new opportunities. J. Bus. Ventur. 2012, 27, 77-94. [CrossRef]

36. Sharon, A.; Barney, B. Discovery and Creation: Alternative theories of entrepreneurial action. Strateg. Entrep. J. 2007, 1, 11-26.

37. Argote, L. Organizational Learning: Creating, Retaining and Transferring Knowledge; Kluwer Academic Publishers: Norwell, MA, USA, 1999.

38. Politis, D. The process of entrepreneurial learning: A conceptual framework. Entrep. Theory Pract. 2005, 29, 399-424. [CrossRef]

39. Dubickis, M.; Gaile-Sakane, E. Transfer of know-how based on learning outcomes for development of an open innovation. J. Open Innov. Technol. Mark. Complex. 2017, 3. [CrossRef]

40. Venkataraman, S. The distinctive domain of entrepreneurship research: An editor's perspective. In Advances in Entrepreneurship, Firm Emergence, and Growth; Katz, J., Brockhaus, R., Eds.; JAI Press: Greenwich, CT, USA, 1997.

41. McMullen, J.S.; Shepherd, D.A. Entrepreneurial action and the role of uncertainty in the theory of the entrepreneur. Acad. Manag. Rev. 2006, 31, 132-152. [CrossRef]

42. Li, Z. Entrepreneurial Alertness: An Exploratory Study. Ph.D. Dissertation, Case Western Reserve University, Cleveland, OH, USA, January 2004, unpublished.

43. Valliere, D. Towards a schematic theory of entrepreneurial alertness. J. Bus. Ventur. 2013, $28,430-442$. [CrossRef]

44. Jiao, H.; Cui, Y.; Zhu, Y.; Chen, J. Building entrepreneurs' innovativeness through knowledge management: The mediating effect of entrepreneurial alertness. Technol. Anal. Strateg. Manag. 2014, 26, 501-516. [CrossRef]

45. Fiet, J.O. A Prescriptive Analysis of Search and Discovery. J. Manag. Stud. 2007, 44, 592-611. [CrossRef]

46. Diga, M.; Kelleher, T. Social media use, perceptions of decision-making power, and public relations roles. Public Relat. Rev. 2009, 35, 440-442. [CrossRef]

47. McKelvie, A.; Wiklund, J. How knowledge affects opportunity discovery and exploitation among new ventures in dynamic markets. In Research in Entrepreneurship and Management; Butler, J., Ed.; Information Age Publishing: Greenwich, CT, USA, 2004; Volume 4, pp. 219-240.

48. Kolb, D.A. Experiential Learning: Experience as the Source of Learning and Development; Prentice Hall: Englewood Cliffs, NJ, USA, 1984.

49. Podsakoff, P.M.; MacKenzie, S.B.; Lee, J.Y.; Podsakoff, N.P. Common method biases in behavioral research: A critical review of the literature and recommended remedies. J. Appl. Psychol. 2003, 88, 879-903. [CrossRef] [PubMed] 
50. Leftheriotis, I.; Giannakos, M. Using social media for work: Losing your time or improving your work? Comput. Hum. Behav. 2014, 31, 134-142. [CrossRef]

51. Ringle, C.M.; Wende, S.; Will, A. SmartPLS 2.0 (M3), Hamburg: SmartPLS. 2005. Available online: http:/ / www.smartpls.com (accessed on 10 May 2017).

52. Fornell, C.; Larcker, D.F. Evaluating structural equation models with unobservable variables and measurement error. J. Mark. Res. 1981, 18, 39-50. [CrossRef]

53. Chin, W.W. The partial least squares approach for structural equation modeling. In Modern Methods for Business Research; Marcoulides, G.A., Ed.; Lawrence Erlbaum Associates: London, UK, 1998; pp. 295-336.

54. Myers, R.H. Classical and Modern Regression with Applications; Duxbury/Thomson Learning: Pacific Grove, CA, USA, 1990.

55. Genc, M.; Oksuz, B. A fact or an illusion: Effective social media usage of female entrepreneurs. Procedia Soc. Behav. Sci. 2015, 195, 293-300. [CrossRef]

56. Kane, G. Why Social Media will Fundamentally Change Business. MIT Sloan Manag. Rev. 2014. Available online: http://sloanreview.mit.edu/article/why-social-media-will-fundamentally-changebusiness / (accessed on 2 September 2017).

57. Power, D. What Is the Impact of Social Media on Decision Making? Available online: DSSResources.com (accessed on 10 May 2011).

58. Porter, M.; Anderson, B.; Nhotsavang, M. Anti-social media: Executive Twitter "engagement" and attitudes about media credibility. J. Commun. Manag. 2015, 19, 270-287. [CrossRef]

59. Taylor, M.; Kent, M. Anticipatory socialization in the use of social media in public relations: A content analysis of PRSA's public relations tactics. Public Relat. Rev. 2010, 36, 207-214. [CrossRef]

60. Yun, J.H. How do we conquer the growth limits of capitalism? Schumpeterian Dynamics of Open Innovation. J. Open Innov. Technol. Mark. Complex. 2015, 1. [CrossRef]

61. DiStaso, M.; McCorkindale, T.; Wright, D. How public relations executives perceive and measure the impact of social media in their organizations. Public Relat. Rev. 2011, 37, 325-328. [CrossRef]

62. Cassar, G. Industry and startup experience on entrepreneur forecast performance in new firms. J. Bus. Ventur. 2014, 29, 137-151. [CrossRef]

63. Marvel, M.; Lumpkin, G.T. Technology Entrepreneurs' Human Capital and Its Effects on Innovation Radicalness. Entrep. Theory Pract. 2007, 807-828. [CrossRef]

64. Kankanhalli, A.; Tan, B.C.Y.; Wei, K.K. Contributing knowledge to electronic knowledge repostitories: An empirical investigation. MIS Q. 2005, 29, 113-143. 